\title{
Possible applications of salvianolic acid B against different cancers
}

\author{
Iram Shahzadi ${ }^{1}$, Zain Ali $^{2}$, Sidra Bukhari ${ }^{2}$, Acharan S Narula ${ }^{3}$, Bushra Mirza $^{{ }^{*}}$, Reza Mohammadinejad ${ }^{*}$ \\ ${ }^{1}$ Plant Molecular Biology Lab, Institute of Biological Sciences, Department of Biochemistry, Quaid i Azam University, Islamabad \\ 45320, Pakistan \\ ${ }^{2}$ Molecular Cancer Therapeutics Lab, Institute of Biological Sciences, Department of Biochemistry, Quaid i Azam University, \\ Islamabad 45320, Pakistan \\ ${ }^{3}$ Narula Research, Chapel Hill, NC 27516, USA \\ ${ }^{4}$ Neuroscience Research Center, Institute of Neuropharmacology, Kerman University of Medical Sciences, Kerman \\ 7619813159, Iran
} *Correspondence: Bushra Mirza, Plant Molecular Biology Lab, Institute of Biological Sciences, Department of Biochemistry,
Quaid i Azam University, Islamabad 45320, Pakistan. bushramirza@qau.edu.pk; Reza Mohammadinejad, Neuroscience
Research Center, Institute of Neuropharmacology, Kerman University of Medical Sciences, Kerman 7619813159, Iran.
r.mohammadinejad87@gmail.com

Academic Editor: Gautam Sethi, National University of Singapore, Singapore

Received: May 7, 2020 Accepted: July 6, 2020 Published: August 31, 2020

Cite this article: Shahzadi I, Ali Z, Bukhari S, Narula AS, Mirza B, Mohammadinejad R. Possible applications of salvianolic acid B against different cancers. Explor Target Antitumor Ther. 2020;1:218-38. https://doi.org/10.37349/etat.2020.00014

\begin{abstract}
Cancer is the second death causing disease worldwide after cardiovascular abnormalities. The difficulty in treating tumor cells with more precise targeted interventions and recurrence of cancer after treatment may pose great difficulty in developing sustainable therapeutic regimens. These limitations have prompted the need to explore several compounds with ability to cease tumor growth while at the same time induce apoptosis of tumor cells. Several studies have emphasized the use of natural compounds as antitumor agents due to their high efficacy against cancer cells and low toxicity in normal cells. Salvianolic acid B (SAB), a naturally occurring phenolic compound extracted from the radix of Chinese herb Salvia miltiorrhiza can induce apoptosis in different types of tumor cells. It can be used to treat cardiovascular and neurodegenerative disorders, hepatic fibrosis, and cancers. Several studies have shown that SAB can mitigate tumorigenesis by modulating MAPK, PI3K/AKT, and NF-KB signaling pathways. It also sensitizes the tumor cells to different anti-cancer agents by reversing the multi-drug resistance mechanisms found in tumor cells. This review summarizes the studies showing antitumor potential of SAB in different types of cancer cell lines, animal models and highlights the possible mechanisms through which SAB can induce apoptosis, inhibit growth and metastasis in tumor cells. Moreover, the possible role of nano-technological approaches to induce targeted delivery of SAB to eradicate tumor cells has been also discussed.
\end{abstract}

\section{Keywords}

Salvianolic acid B, polyphenols, apoptosis, molecular targets, cancer 


\section{Introduction}

A report published by World Health Organization (WHO) has documented that cancer is the second highest cause for death around the world and $70 \%$ of deaths because of different cancers have been reported in middle- and low-income countries. Cancer rates could increase by $50 \%$ to 15 million new cases a year by the year 2020 [1-3]. Cancer is mainly caused by various mutations in the genome, which can cause deregulation of diverse molecular signaling cascades [4-6]. The presence of constant growth signals, unresponsiveness to antigrowth signals, apoptosis resistant, heightened angiogenesis, tissue invasion in addition to metastasis, enhanced replicative potential, as well as genome variabilities are the major signs of cancerous cell growth [7]. Numerous therapeutic approaches against cancer have been established over the last few decades after acquiring a deeper understanding of several underlying signaling mechanisms that can lead to the enhanced survival and proliferation of neoplastic cells. They include adjuvant and neoadjuvant chemotherapy, targeted therapy, immunotherapy, surgery, and radiotherapy [8-11]. The prevalence of cancer and mortality remains high despite substantial improvements in treatment procedures [12]. This phenomenon can be generally attributed to the limited effects of existing anti-cancer therapies and the expensive cost of the treatment, in addition to substantial adverse reactions [13]. Additionally, modern cytotoxic agents commonly possess life-threatening toxicity $[14,15]$. In the past six decades, there have been several cases of removal of pharmaceutical products from the market because of antagonistic drug reactions, with the most prominent adverse event being hepatotoxicity [16]. Additionally, some cancers such as breast cancer may often reappear after remaining inactive for a long time even after successful treatment [17], indicating that discovery of new and safe treatment methods is still needed.

Mother Nature is a reservoir of a significant number of plant-based natural products, which possess significant anti-cancer potential [18]. Several plant-based molecules can act as a chemosensitizer as well as overcome chemoresistance in different types of cancer [19-23]. In addition, $40 \%$ of the medicines approved by the FDA available in the market have been derived from products obtained from plants, $74 \%$ of which are anticancer drugs [24, 25]. The research in this field has emphasized on the utilization of undiscovered reservoirs of phytochemicals such as alkaloids, glycosides, terpenoids, phenolics, and saponins, in order to avoid the harmful side effects of medications used in chemotherapy, to prolong recovery time as well as to boost the quality of life in cancer patients $[5,19,26,27]$. Salvia miltiorrhiza (S. miltiorrhiza, Danshen) belongs to the family Labiatae, is a well-known traditional Chinese herb. In addition, due to its excellent medicinal properties, it has been in use for thousands of years to treat many diseases and is regarded as "Super-grade drug" in Pen-Ts'ao of Shen-Nung [28]. Traditionally, Danshen has been extensively used to treat cardiovascular diseases, mental agitation, memory weakness, insomnia, cancer, and liver fibrosis [29-31]. It also delays the development of atherosclerosis [32]. Its role as an anti-hypertensive and anti-platelet aggregation agent also may result in the prevention of cerebral infarction [33]. Danshen may have a role in the elevated expression of certain antioxidant enzymes [34].

Pharmacologically, Danshen has two categories of compounds, $\mathrm{i}=$ lipophilic diterpenoid tanshinones, ii = water-soluble phenolic acids [35]. Tanshinones are important antioxidants, anti-cardiovascular, antiinflammatory, and antitumor agents and are the main ingredient in S. miltiorrhiza [36]. The water-soluble phenolic acids possess various bioactivities including those of antioxidant, anticoagulant, anti-thrombotic, antitumor, and anti-HIV [37]. Among the water-soluble phenolic acids, salvianolic acid B (SAB) is the chief component as per official Chinese Pharmacopoeia. Many studies have reported the promising antitumor, neuroprotective and cardio-protective properties of SAB in different model systems [38-40]. This review briefly highlights the important cellular pathways involved in the antitumoral actions of SAB in different cancer cell lines and in animal models and strategies to utilize its potential for cancer therapy.

\section{SAB chemistry}

The basic chemical structure of different derivatives of SAB contain [(R)-3-(3, 4-dihydroxyphenyl)-2hydroxypropanoic acid] and it is also known as lithospermic acid B [41]. Molecular formula of $\mathrm{SAB}_{\text {is }} \mathrm{C}_{36} \mathrm{H}_{30} \mathrm{O}_{16}$ and its molecular weight is $718.6138 \mathrm{~g} / \mathrm{mol}$. SAB is yellowish and an amorphous compound formed by three 
Danshensu (salvianic acid A) molecules and one molecule of caffeic acid. Interestingly, phenolic groups in different compounds are responsible for inhibition of tumor invasion, induction of apoptosis, reversal of drug resistance, modulation of immune response to tumor cells, inhibition of metastasis of tumor cells, and reducing abnormal proliferation [42]. Blocking of lipid peroxidation can be executed by release of hydrogen from activated phenolic hydroxyl groups ( 9 in number) [43]. Interestingly, antioxidant activities demonstrated by SAB and Danshensu have been attributed to the functional phenolic groups present in their structures [44, 45]. Chemical structure of SAB were shown in Figure 1.

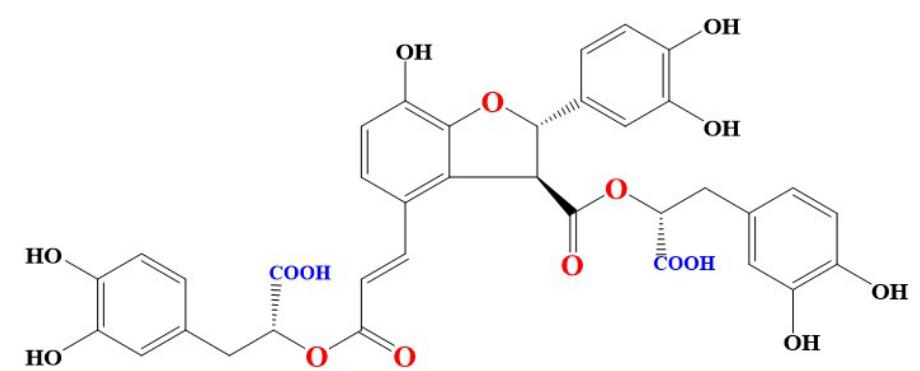

Figure 1. Chemical structure of salvianolic acid $B$

\section{Biosynthesis of SAB}

Among different salvianolic acids, SAB and rosmarinic acid (RA) can be synthesized primarily through tyrosine derived phenolic acid and phenylpropanoid biosynthetic pathways (Figure 2) [46]. Biosynthesis of RA is initiated when $L$-phenylalanine and $L$-tyrosine are converted to two different intermediates, i.e. 4-coumaroyl-CoA and 4-hydroxyphenyllactic acid respectively by two parallel but independent pathways. Several subsequent biochemical reactions initiated by covalently joining these two intermediates can form $\mathrm{RA}$ at the end. SAB is thought to be derived from RA (Figure 2). However, the detailed mechanism of SAB synthesis has not been studied until date [47]. The extent/quantification of biosynthesis of SAB is dependent on the yield recovered during its extraction process. In general, using conventional reflux-based extraction methods for extraction from roots requires high temperature for a longer time, which may contribute to a lower yield of SAB mainly due to its hydrolysis into tanshinol [48]. However, a higher extraction yield can be achieved over a shorter time and lower temperature when an ultrasound-assisted extraction method is used. Using the ultrasound-assisted extraction method, the yield of salvianolic acid B was $33.93 \mathrm{mg} / \mathrm{g}$ in S. miltiorrhiza roots higher than those with a conventional refluxing method $(28.76 \mathrm{mg} / \mathrm{g})$ [49].

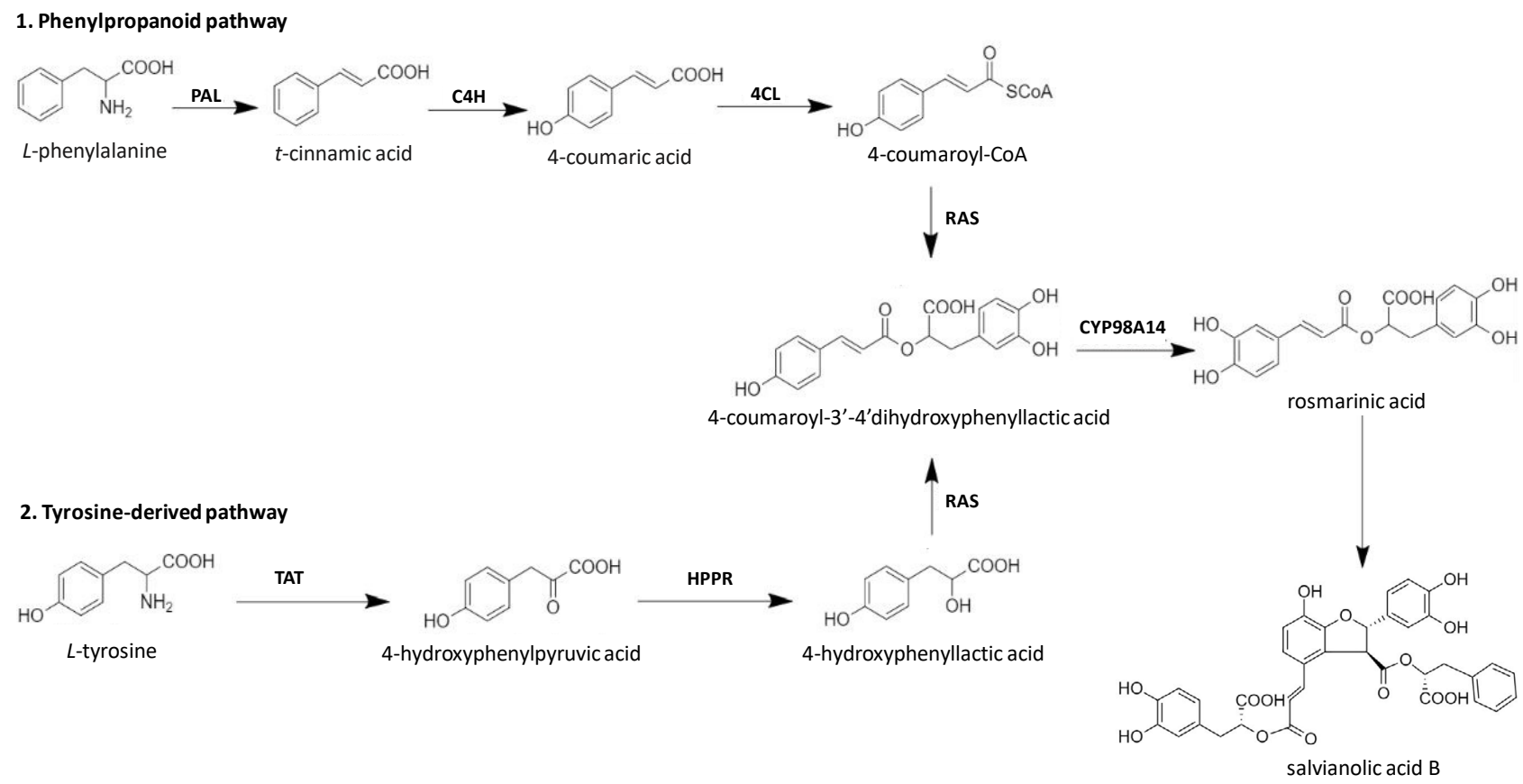

Figure 2. Biosynthetic pathways of SAB in S. miltiorrhiza. TAT: tyrosine amino transferase; HPPR: 4-hydroxyphenylpyruvate reductase; PAL: phenylalanine ammonia-lyase; $\mathrm{C} 4 \mathrm{H}$ : cinnamic acid 4-hydroxylase; 4CL: 4-coumarate CoA ligase; RAS: rosmarinic acid synthase; CYP98A14: cytochrome P450-dependent monooxygenase 


\section{Various molecular targets affected by SAB}

As cancer is a disease in which several signaling molecules may be deregulated causing the cells to multiply, invade, or metastasize [50]. SAB has been identified as a potential antitumor compound and has been observed to target multiple steps in the apoptotic pathway [51] (Figure 3). The studies on the mechanistic action of SAB showed up-regulation of caspase-9, pro-apoptotic proteins, i.e. B-cell lymphoma 2 (BCL-2)associated X protein (BAX) and BAK, enhanced caspase-3 level with poly ADP-ribose polymerase (PARP) cleavage and down-regulation of anti-apoptotic proteins such as Bcl-2, which can promote apoptosis [52-55]. In SKOV3 ovarian cancer cells, SAB induced apoptosis by the activation of caspase- 3 in a dose-dependent manner [56]. It was also found to cause cell cycle arrest at M/G2 phase by inhibiting the expression of cyclin E and cyclin D [57, 58].

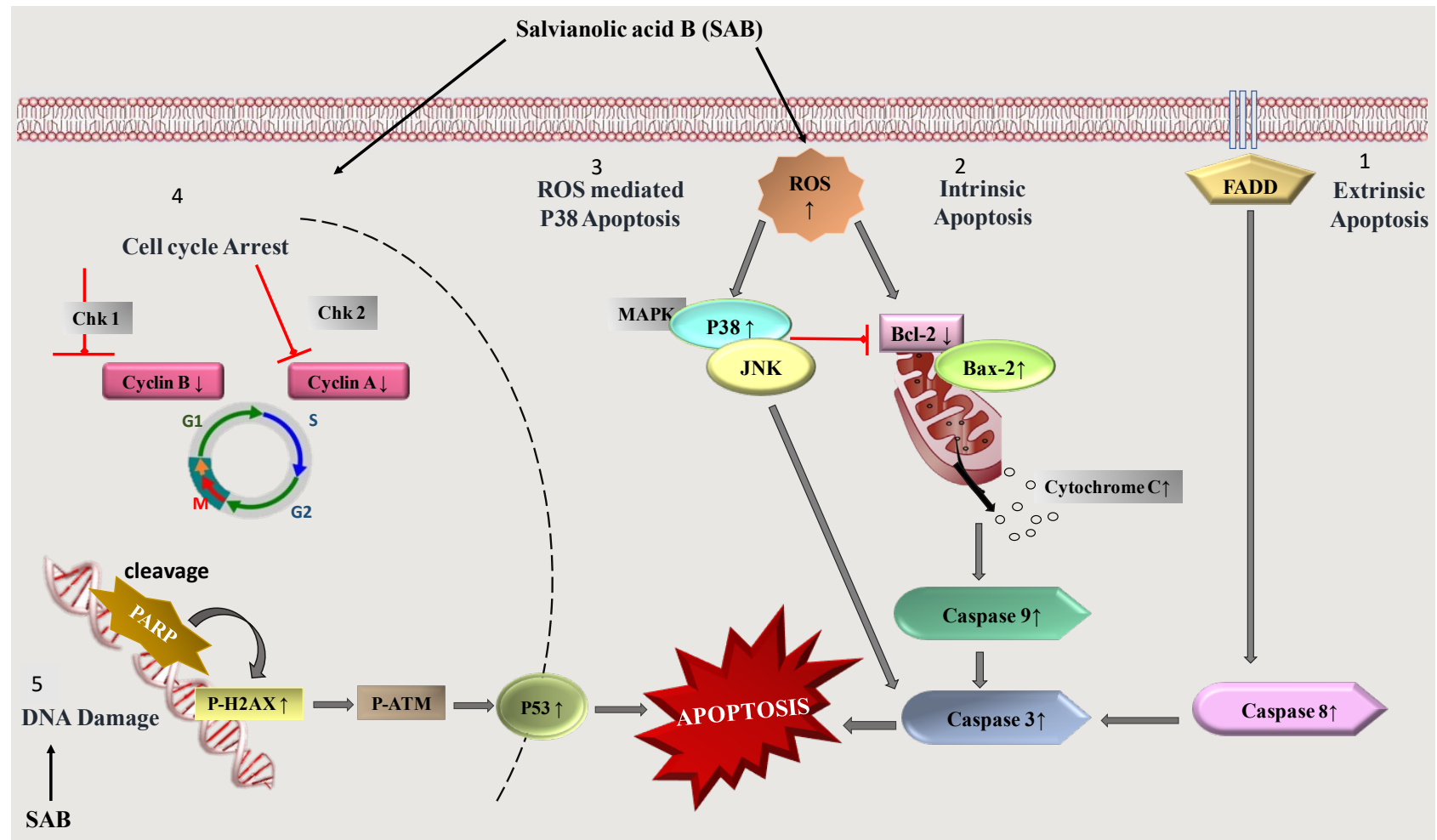

Figure 3. A diagram showing the induction of apoptosis and cell cycle arrest induced by SAB treatment. FADD: FAS-associated death domain protein; JNK: c-Jun N-terminal kinase; MAPK: mitogen-activated protein kinase; Chk: Checkpoints; $\uparrow$ increase; $\downarrow$ decrease

In addition, among several signal transduction pathways, phosphatidylinositol 3-kinase (PI3K)/protein kinase B (AKT) has been found to be deregulated in most types of tumor cells. PI3K/AKT, a serine-threonine kinase protein binds to phosphatidylinositol triphosphate (PIP3) on the surface of a cell and its activity can be modulated by phosphoinositide dependent kinase-1 (PDK-1) after its binding to PIP3. Activated AKT can phosphorylate downstream target proteins, including forkhead box 0 (FOX01), glycogen synthase kinase-3 (GSK3 $\beta$ ), and mTOR, resulting in cancer cell survival, cell-cycle progression, ribosome biogenesis, and/or protein synthesis [59]. AKT and mTOR are the key proteins involved in regulation of apoptotic and autophagy pathways in different tumor cells. Therefore, it represents a potential antitumor target in therapeutic studies [60-62]. SAB has been found to induce apoptosis and autophagy by inhibiting AKT/PI3K mediated activation of mTOR pathway in colorectal [63] and hepatocellular carcinoma (HCC) cells [60]. Autophagy is an important physiological process, which has been reported to be involved in the maintenance of cellular homeostasis by degrading old proteins and damaged cellular organelles [64]. Autophagy plays a dual role in cancer. It may be involved in tumor suppression as well as in increased proliferation. Apoptosis and autophagy could be induced by the same stimulus, but the interaction between them was still unclear [65]. Most studies have shown effects of SAB on PI3K/AKT signaling pathway resulting in down-regulation of m-TOR. There is need to explore further molecular targets modulated by SAB within PI3K/AKT pathway, i.e. FOXOs and GSK3 $\beta$ as they are also involved in the process of cell survival and cell cycle progression in tumor cells [66]. 
Tumor cells exhibit elevated activation of constitutive nuclear factor kappa light chain enhancer of activated B cells (NF- $\mathrm{\kappa B}$ ), which may lead to increased cell growth, reduced apoptosis, metastasis of tumor cells, angiogenesis and alter cellular metabolism by regulating the expression of many genes such as cyclooxygenase-2 (Cox-2) [67-69]. NF- $\kappa B$ activation can cause tumor cells to become resistant to apoptosis and it can facilitate increased proliferation and metastasis [70-72]. NF- $\kappa B$ has been considered as an important target for modulation by different therapeutic approaches in many tumor types $[73,74]$. NF- $\mathrm{KB}$ and MDM-2 (mouse double minute 2 homolog) were found to be down-regulated in SAB treated JHU-013 head and neck cancer cells in a dose-dependent sequential inhibition of LPS-stimulated Cox-2 and PGE-2 [57, 58]. The mechanism(s) by which SAB can exert its inhibitory effects on NF-kB pathway is still unclear and requires detailed studies. In 7,12-dimethylbenzanthracene (DMBA) treated hamster model, modifications of key metabolic pathways, including elevated glutaminolysis and glycolysis, and decreased cholesterol and myo-inositol metabolism were observed, which were attenuated by SAB exposure. SAB also inhibited important regulators of cellular proliferation and tumorigenesis, i.e. hypoxia induced factor (HIF)-1 $\alpha$, matrix metalloproteinase (MMP)-9, and tumor necrosis factor (TNF) $\alpha[75,76]$. The action of SAB in modulating Warburg effect and affecting tumor growth were summarized in Figure 4.

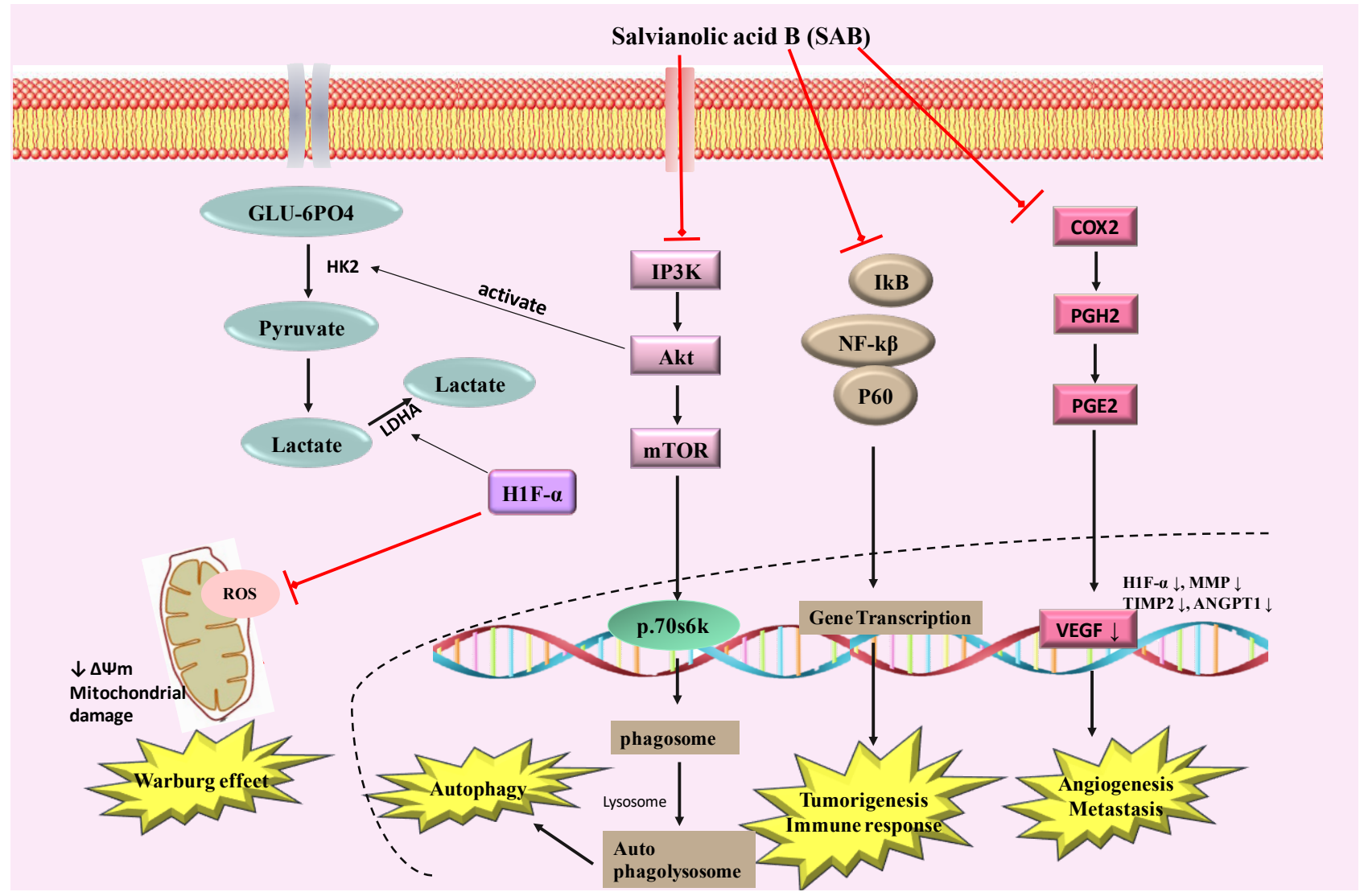

Figure 4. Schematic diagram showing SAB inducing mechanism of action in cancer. PGH2: prostaglandin H2; PGE2: prostaglandin E2; VEGF: vascular endothelial growth factor; MMP: matrix metalloproteinases; IP3K: indole phosphatide 3 kinase; GLU-6PO4: glucose 6 phosphate; $\uparrow$ increase; $\downarrow$ decrease

A brief overview of anti-cancer potential of SAB in different tumor malignancies, i.e. breast cancer, HCC, leukemia, colorectal cancer, head and neck squamous cell carcinoma (HNSCC), glioma cells, cervical cancer, ovarian cancer, and retinoblastoma has been shown in tables 1 and 2 . The detailed pharmacological impact of SAB against different cancers has been discussed briefly below:

\section{Breast cancer}

Breast cancer remains a leading cause of cancer related deaths in females worldwide [77-80]. Chemotherapy is the most common way to treat breast tumors despite some limitations including high toxicity, normal cell death, and increase in drug resistance [81, 82]. The proliferation of hormone receptor-positive breast cancer cell line (MCF-7) was decreased by SAB in vitro. It also attenuated the tumor volume and increases the survival 
of Ehrlich solid carcinoma cell line (ESC) injected mice. Furthermore, in a preclinical study, SAB decreased the plasma level of glutathione (GSH) and malondialdehyde in mice. In ESC injected mice, it decreased the expression of MMP-8, TNF $\alpha$, Cox-2, and level of cyclin D1 in combination with cisplatin. It also increased the expression level of p53 and caspase-3 [83]. Triple-negative breast cancer (TNBC) is an aggressive subtype of breast cancer with limited treatment options [82]. Moreover, an in-vitro study showed a significant reduction in proliferation and decreased expression of cyclin B1 expression in hormone receptor-positive MCF-7 and triple-negative MDA-MB-231 breast cancer cell lines by SAB. In mouse model, the inhibition of growth, increased apoptosis, and decreased expression of proliferating cell nuclear antigen (PCNA) was observed in MDA-MB-231 tumor xenograft mouse model. SAB also caused an enhanced accumulation of ceramide and inhibited the expression of survivin and Bcl-xL [84]. These effects showed that SAB could be an effective therapeutic compound against breast cancer.

Table 1. Selected anticancer effects of SAB on tumor cell lines

\begin{tabular}{|c|c|c|c|c|}
\hline Type of cancer & Model/cell line & Morphological effects & Mechanisms of action & References \\
\hline \multirow[t]{2}{*}{ Oral cancer } & $\begin{array}{l}\text { CAL27, SCC4, } \\
\text { Leuk1 }\end{array}$ & $\begin{array}{l}\text { Apoptosis, inhibits cell growth, } \\
\text { anti-angiogenesis }\end{array}$ & $\begin{array}{l}\downarrow \text { HIF-1 } \alpha, \downarrow \text { TNF } \alpha, \downarrow \text { MMP9, } \downarrow \text { Tenascin-C, } \\
\downarrow \text { Osteopontin, } \downarrow \text { TGF } \beta, \downarrow \text { Cox-2, } \downarrow \text { HGF, } \\
\downarrow \text { MMP2, } \text { THBS2 }\end{array}$ & {$[75,76]$} \\
\hline & $\begin{array}{l}\text { CAL27, HN4, and } \\
\text { Leuk1 }\end{array}$ & $\begin{array}{l}\text { Apoptosis, inhibits cell growth, } \\
\text { modulates Warburg effect }\end{array}$ & $\downarrow \mathrm{MMP}, \downarrow \mathrm{PI} / \mathrm{K} / \mathrm{Akt} / \mathrm{HIF}-\alpha$ & [123] \\
\hline Leukemia & HL-60 & Apoptosis, inhibits cell growth & - & [125] \\
\hline Cervical cancer & $\begin{array}{l}\text { Hela cells } \\
\text { SAB + ATO }\end{array}$ & Apoptosis, inhibits cell growth & $\downarrow$ pro-caspase $3, \uparrow P A R P$ cleavage & {$[96]$} \\
\hline Retinoblastoma & HXO-RB44 & $\begin{array}{l}\text { Apoptosis, cell volume } \\
\text { shrinkage, chromatics } \\
\text { agglutination, inhibits cell } \\
\text { growth, cell cycle arrest at S } \\
\text { phase }\end{array}$ & $\uparrow$ caspase 3 & [117] \\
\hline
\end{tabular}

$\uparrow$ increases expression, $\downarrow$ decreases expression

Table 2. Selected in vivo anticancer effects of $S A B$

\begin{tabular}{|c|c|c|c|c|}
\hline $\begin{array}{l}\text { Type of } \\
\text { cancer }\end{array}$ & $\begin{array}{l}\text { Mouse/mice/hamster } \\
\text { model }\end{array}$ & Morphological effects & Mechanism(s) of action & References \\
\hline \multirow[t]{2}{*}{ Breast cancer } & Mouse model & $\begin{array}{l}\text { Apoptosis induction, reduction } \\
\text { of oxidative stress, anti- } \\
\text { inflammatory, anti-angiogenesis }\end{array}$ & $\begin{array}{l}\downarrow \mathrm{MMp}-8, \downarrow \text { TNF, } \downarrow \text { COX-2, } \downarrow \text { p53, } \\
\uparrow \text { caspase } 3\end{array}$ & [83] \\
\hline & Mouse model & $\begin{array}{l}\text { Increased cell apoptosis, } \\
\text { inhibition of growth }\end{array}$ & $\downarrow P C N A, \downarrow$ Survivin, $\downarrow$ BCL-XL & {$[84]$} \\
\hline \multirow[t]{2}{*}{ Colon cancer } & $\begin{array}{l}\text { LoVo cells HCT- } 116 \\
\text { cells nude mice }\end{array}$ & $\begin{array}{l}\text { Inhibits tumor growth, inhibits } \\
\text { tumor invasion, multidrug } \\
\text { resistance }\end{array}$ & $\downarrow \mathrm{CD} 44, \downarrow \mathrm{CD} 133, \downarrow \mathrm{SOX}-2, \downarrow \mathrm{ABCG} 2$ & [108] \\
\hline & $\begin{array}{l}\text { BALB/c nude mice } \\
\text { injected with HCT116 } \\
\text { cells }\end{array}$ & Pro-death autophagy & $\begin{array}{l}\uparrow \text { Atg5 expression, } \perp \text { AKT/mTOR } \\
\text { signaling pathway, } \downarrow \text { p70S6K }\end{array}$ & [63] \\
\hline Glioma & $\begin{array}{l}\text { U87 xenograft nude } \\
\text { mice }\end{array}$ & $\begin{array}{l}\text { Tumor volume reduced, weight } \\
\text { reduced, increases ROS }\end{array}$ & $\uparrow p 38, \uparrow p 53$ & [111] \\
\hline Oral cancer & Hamster & $\begin{array}{l}\text { Antiproliferative, inhibition of } \\
\text { angiogenesis }\end{array}$ & $\downarrow H I F-1 \alpha, \downarrow$ VEGF & {$[122,123]$} \\
\hline $\begin{array}{l}\text { Head and } \\
\text { neck cancer }\end{array}$ & $\begin{array}{l}\mathrm{JHU}-013 \text { xenograft } \\
\text { mouse }\end{array}$ & $\begin{array}{l}\text { Apoptosis, anti-proliferative, } \\
\text { angiogenesis }\end{array}$ & $\downarrow$ COX-2 & {$[57,58]$} \\
\hline
\end{tabular}

$\uparrow$ increase expression, $\downarrow$ decrease expression, $\perp$ inhibit

\section{HCC}

HCC is the carcinoma of liver, which ranks third at causing cancer related deaths and is the fifth most common cancer of the world [85-87]. Mostly hepatitis B and C virus are associated with the HCC development in the patients [88]. Different chemotherapeutic drugs as well as targeted therapies are available for HCC treatment but now due to their numerous side effects, natural drugs are also being used [6, 25, 89-94]. In an earlier study, it was observed that $\mathrm{SAB}$ can inhibit the cell proliferation at a higher dose, downregulate the 
expression of cytochromes CYP1A2 and CYP3A4 and upregulate the expression of GSH S-transferase (GST) in HepG2 human hepatoma cell lines [95]. The combination of SAB with arsenic trioxide (ATO) enhanced the cytotoxicity of ATO as well as induced apoptosis in HepG2 cell lines with decreased expression of procaspase-3 and increased expression of cleaved PARP that is an apoptotic marker [96].

SAB has also shown the potential to inhibit the growth of SK-Hep-1 and Bel-7404 HCC cell lines, induce autophagy, and promote apoptosis through activating mitochondrial pathway leading to cancer cell death. This can be achieved by inhibition of AKT/mTOR signaling pathway in-vitro in HCC lines. SAB downregulated the mTOR levels, phosphorylated AKT along with its downstream effector p-4EBP1 and p70S6K proteins, thus inhibiting cellular growth, proliferation, and metabolism. Suppression of autophagy by pharmacological inhibitors (3-MA and CQ) or Beclin-1 siRNA decreased SAB-induced apoptosis, thus revealing the role of autophagy in promoting apoptosis [60].

\section{HNSCC}

Head and neck cancer rank among the top ten cancers [97-99]. This cancer is mainly associated with tobacco exposure [100] and a number of inflammatory pathways are involved in the development of HNSCC [101, 102]. Different studies have indicated that SAB can exhibit chemo-preventive effects against HNSCC [103]. SAB caused a decrease in the expression of Cox- 2 and induced apoptosis in a variety of head and neck carcinoma [58]. SAB attenuated the tumor growth in JHU-013 xenograft mice and decreased the expression of Cox-2 substantially with apoptosis induction $[57,58]$. It also inhibited proliferation in four HNSCC cell lines (JHU-06, JHU-011, JHU-013, and JHU-022) [103].

\section{Colorectal cancer}

Colorectal cancer is the third most death causing cancer worldwide [104, 105]. In colorectal cancer patients, 5-year survival rate generally after diagnosis is around 50-55\% [106]. Chemotherapy for colorectal cancer is the ideal choice of intervention but drug resistance often hampers the success of therapy. Thus, there is an urgent need to address drug resistance in colorectal cancer. SAB reduced cell proliferation and increased apoptosis in colorectal cancer cells (HCT-8/VCR) at different concentrations. SAB showed IC ${ }_{20}$ (concentration needed to kill cells by $20 \%$ as compared to untreated control) of $20.79 \pm 4.76 \mu \mathrm{g} / \mathrm{mL}$ and IC (concentration $_{50}$ needed to kill cells by $50 \%$ as compared to untreated control) of $114.79 \pm 10.94 \mu \mathrm{g} / \mathrm{mL}$ against HCT-8/VCR cells. At non-toxic concentration, SAB enhanced the effects of VCR, CDDP, Taxol, and 5-fluorouracil (5-FU) by inhibiting drug resistance in colorectal cancer cells. $S A B$ also reversed the multi-drug resistance (MDR) of colorectal cancer cells by causing a down-regulation of P-gp protein, which subsequently enhanced the sensitivity of colorectal cells to these drugs and increased expression of pro-apoptotic mitochondrial protein Bax while causing a down-regulation of anti-apoptotic Bcl-2. SAB enhanced ROS production that leads to reduction in mitochondrial membrane potential and increased cell death [107]. In-vivo studies using nude mice injected with colorectal cancer cells (LoVo \& HCT-116) showed reversal of drug resistance, reduced tumor cell invasion, and increased apoptosis. Tumor invasion markers such as CD44, CD133, ABCG-2 and Sox-2 were down-regulated. In addition, 5-FU and L-OHP showed greater efficacy, reduced tumor growth, and increased apoptosis when injected in combination with SAB as compared to 5-FU and L-OHP alone. These findings suggested potential of SAB to attenuate drug resistance in colorectal cells [108].

Moreover, SAB induced substantial autophagy in HCT116 and HT29 colorectal cells and in-vivo in HCT116 injected BALB/c nude mice. The expression of caspase-3, caspase- 9 , and PARP was elevated after SAB exposure. It also induced autophagy by inhibiting AKT/mTOR signaling pathways. Transfection of AKT plasmid in colorectal cells reduced SAB induced autophagy while repression of AKT signaling pathway by LY294002 (PI3K inhibitor) increased SAB mediated autophagy [63].

\section{Glioma}

Glioma is the leading cause of brain-related tumor's death worldwide and it can affect the central nervous system [109]. The rate of survival is generally less than $5 \%$ and the average life expectancy of individuals diagnosed with glioblastoma, an aggressive subtype of Glioma is 12-14 months [110]. Treatment of human 
primary glioblastoma cell line (U87) with $50 \mu \mathrm{mol} / \mathrm{L}$ SAB inhibited growth and increased apoptosis in a dosedependent manner. SAB treated U87 glioma xenograft nude mice showed reduced tumor volume and weight. The apoptosis induction and reduced growth in glioma cells was primarily mediated through p38MAPK and p53 activated ROS pathways [111].

Radiation therapy is the standard mode of treatment in glioma patients. There is an increased resistance to radiation by glioma cells, which may result in the failure of therapy. At $0.5 \mu \mathrm{mol} / \mathrm{L}$ concentration, $\mathrm{SAB}$ did not affect the viability of glioma cells but increased the efficacy of radiotherapy in U87 (human primary glioblastoma cell line). SAB did not have any effect on the sensitivity of temozolomide (TMZ) at this concentration. SAB increased the antitumor potential of radiotherapy by increasing mitochondrial fission and activating mitochondrial fission proteins. Overall, SAB rendered radiotherapy more effective in glioma cells by increased mitochondrial fission through Fis-1 mediated mitochondrial fission [112].

\section{Cervical cancer}

Cervical cancer is the fourth most prevalent type of cancer in women [113]. Combinatorial administration of SAB with ATO drug showed enhanced antitumor activity against cervical cancer cells (HeLa) and antitumor effect was found to be apoptosis dependent. As compared to control cells, ATO and SAB treated HeLa cells displayed enhanced caspase- 3 mediated PARP cleavage after $48 \mathrm{~h}$ of treatment. This indicated that SAB may have an important role as an antitumor drug in cervical cancer [96].

\section{Ovarian cancer}

Ovarian cancer is the fifth most prevalent cancer among women worldwide [114]. Chemotherapy and surgery are the most common type of interventions used to curb the deleterious effects of ovarian cancer. Ovarian tumor cells are prone to develop drug resistance over time and this leads to recurrence of ovarian cancer after treatment [115]. There is an imminent need to explore candidate antitumor compounds, which reduce the growth of ovarian cancer cells with minimal effects on normal cells. SAB showed antitumor potential against ovarian cancer cells (SKOV3) with an $\mathrm{IC}_{50}$ value of $45.6 \mu \mathrm{mol} / \mathrm{L}$. The rate of apoptosis was increased at higher concentration of SAB. In addition, it caused blockage of cell cycle at M phase and G-2 phases of cell cycle and a significant increase in the expression of caspase-3 [56].

\section{Retinoblastoma}

Retinoblastoma is a cancer of children and it contributes $4 \%$ of total pediatric cancer prevalence. Its incidence is around 1 out of 18, 000 births [116]. SAB has shown potential as an antitumor drug against retinoblastoma cells (HXO-RB44). It inhibited the growth of HXO-RB44 cells in a time and dose-dependent manner. HXORB44 cells showed significant apoptosis and other morphological changes, i.e. shrinkage of cell volume, vacuoles formation, and chromatic agglutination after treatment with $0.7 \mathrm{mg} / \mathrm{mL}$ dose of SAB at 24,48 and $72 \mathrm{~h}$ of administration. SAB induced apoptosis and blocked the cell cycle at S-phase so that tumor cells cannot enter G-2 phase and the expression of caspase-3 was significantly high after $48 \mathrm{~h}$ of treatment in HXO-RB44 cells. Overall, SAB induced apoptosis, blocked cell cycle and inhibited the proliferation of retinoblastoma cells in concentration and time-dependent manner [117].

\section{Oral cancer}

The number of cases of oral cancer is increasing day by day with decreased survival rate and increased mortality rate $[118,119]$. Oral squamous cell carcinoma (OSCC) is most common among carcinoma of oral cavity and becoming an important health care problem [120]. Conventional treatment generally includes surgery, chemotherapy, and radiation therapy. All of these therapies are showing fewer positive responses therefore need for natural and more efficient drugs is necessary [121]. The effect of SAB was analyzed on OSCC cell lines and it caused an inhibition of growth of OSCC cell lines. SAB decreased the proliferation of squamous cell carcinoma (SCC) in DMBA induced oral cancer in Hamsters. Inhibition of angiogenesis, HIF- $1 \alpha$ and VEGF protein expression was also observed upon SAB exposure through immunohistochemistry from tissue samples obtained from DMBA induced oral cancer in Hamsters [122]. SAB has also shown promising 
antitumor effects on oral squamous carcinoma cells (CAL27 and SCC4) by inhibiting their proliferation and inducing apoptosis in a time-dependent manner. However, it did not cause any significant antitumor effects in immortalized oral leukoplakia cells (Leuk1). SAB induced apoptosis and inhibited tumor cells angiogenesis by inhibiting expression of Cox-2, HGF, MMP-2, HIF- $1 \alpha$, TNF $\alpha$, MMP-9, tenascin, osteopontin as well as transforming growth factor (TGF)- $1 \beta$ and up-regulating the level of THBS-2 [75]. However, additional in-vivo studies are required to confirm the effects of $\mathrm{SAB}$ on various oncogenic markers, and correlation of these effects with clinical outcome will further expedite the use of SAB as an antitumor drug against oral cancers.

Metabolic modulation by SAB may also mediate its anti-cancer actions against SCC. DMBA induced hamsters showed enhanced glycolysis and glutaminolysis, reduced myoinositol and cholesterol metabolism while SAB treated DMBA induced hamsters showed normal effects as compared to altered metabolic conditions of DMBA induced group. Interleukin 10 (IL-10) mRNA expression was reduced while TIMP-2 and ANGPT-1 expression was increased in SAB treated DMBA injected hamsters [76]. Next-generation sequencing of DMBA injected SAB treated hamsters showed down-regulation of PI3K and HIF-1 $\alpha$ signaling pathways. SAB also exhibited inhibitory effects on PI3K-Akt and HIF-1 $\alpha$ pathways in Cal27 and HN4 cell lines. In premalignant Leuk1 cells, SAB treatment resulted in loss of mitochondrial membrane potential, reduced colony formation, and enhanced apoptosis. These findings suggest the role of metabolic modulation by SAB in tumor cells by altering PI3K/Akt and HIF-1 $\alpha$ signaling pathways [123]. SAB also induced apopstosid and inhubit cell growth by decreasing Cox-2 expression in lumg cancer A549 cell line [124].

\section{Role of SAB in regulating epithelial-mesenchymal transition (EMT)}

For tumor growth and spread, epithelial-mesenchymal transition (EMT) is an important process and enhanced expression of mesenchymal genes (Fibronectin, Vimentin, N-Cadherin), as well as reduced expression of epithelial genes (E-Cadherin), are the most important characteristics of EMT [126, 127]. Metastasis poses the biggest hurdle in effective cancer treatment and accounts for $90 \%$ mortality rate caused by different cancers [128-133]. SAB suppressed extracellular matrix modelling and cellular proliferation through inhibition of NF- $\kappa B$ associated activation of MMP-9 and MMP-2 in high glucose induced mesangial cells [134]. In addition, MMP-9 levels were also noted to be significantly downregulated in SAB treated breast cancer cells [83]. Moreover, studies have indicated that $\mathrm{SAB}$ may have a role in the inhibition of EMT by modulating the expression levels of different micro-RNAs. Yu et al. [135] showed that administration of SAB reversed liver fibrosis, repressed Hedgehog pathway and EMT by up-regulation of Patched-1, miR-152, and DNA methyl transferase 1 (DNMT1). In addition, miR-106b, miR-93 and miR-25 were significantly downregulated in TGF- $\beta$ induced EMT [135].

In addition, another study showed a dose-dependent increase in the expression of miR-106b-25 cluster in SAB treated HK-2 human kidney cancer cells. Interestingly, miR-106b can reduce EMT by increasing the expression levels of E-cadherin and lowering expression levels of $\alpha$-smooth muscle actin ( $\alpha$-SMA) [136]. In-vivo studies have also revealed inhibition of TGB- $\beta 1$-induced EMT in SAB treated HK- 2 cells by modulation of TGF- $\beta /$ Smad signaling pathway [137]. Moreover, a reversal of TGF- $\beta 1$ induced EMT in KH- 2 cervical cancer cells by nano-formulation of SAB (HCA-Chi-Ca-SAB) has been reported [138]. These findings suggest the potential role of salvianolic acids in the reversal of EMT in cancer. EMT reversal may also result in the regeneration of already disseminated cancerous cells within the body [139]. Further studies on the exploration of mechanistic pathways involved in EMT reversal by SAB will establish its role and usefulness as an anti-EMT drug.

\section{Pharmacokinetics and bioavailability of SAB}

A number of naturally derived biological compounds have deficiency in distribution, rapid metabolism, excretion, and poor absorption that may restrain their bioavailability [140]. Several experiments have been conducted to study the pharmacokinetics behavior of SAB in humans and animals for instance dogs, rabbits, and rats. The pharmacokinetic profile of $S A B$ in rats was studied using two-compartment open models by subsequent oral course of $200 \mathrm{mg} / \mathrm{kg}$. The absolute/standard SAB bioavailability is $0.022 \%$. Several 
investigations suggested that after oral administration of SAB, $60 \%$ of given $\mathrm{SAB}$ remains in the gut for at least $180 \mathrm{~min}$, thus contributing to its poor bioavailability in the body [141]. Oral bioavailability in dogs was noted to be $1.1 \%$ only, after the administration of SAB doses, i.e. $80 \mathrm{mg} / \mathrm{kg}$ orally, and $9 \mathrm{mg} / \mathrm{kg}$ [142]. The intravenously injected doses with 3,6, and $12 \mathrm{mg} / \mathrm{kg}$ of magnesium SAB in beagle dogs have also been examined. It was evident from the previous studies that the elimination and distribution of SAB were fast enough [143]. The normal urinary excretion rate of SAB reported from the studies was $0.16 \%$. However, the recovery of $\mathrm{SAB}$ from the gastrointestinal (GI) tract was $41.2 \%$ and $23.3 \%$ respectively when the oral course of 10 and $50 \mathrm{mg} / \mathrm{kg}$ doses were applied [143].

The intravenous dose of $\mathrm{SAB}$ in humans exhibited $0.29 \mathrm{~h}$ half-life of SAB's elimination with the application of $100 \mathrm{mg} / \mathrm{kg}$ dose, although the concentration of SAB gradually and quickly increased in the bile. It attained the highest value within $30 \mathrm{~min}$ [144]. It was observed that the concentration of SAB is greater in the bile than in plasma at certain points, which suggested that the hepatobiliary eradication of SAB might imply an active transport [145]. Furthermore, the cumulative absorption concentration of salvianolic acid B was greater in rear jejunum segments than in middle and front segments. SAB has a low oral bioavailability of $4 \%$ due to the confined intestinal permeability [146]. Moreover, human epithelial colorectal adenocarcinoma cells (Caco-2) study revealed the lower concentration of SAB in cell membrane permeability. About $5 \%$ of SAB bioavailability was noted after oral administration [147]. One hundred $\mathrm{mg} / \mathrm{kg} \mathrm{SAB}$ was administered intravenously, and 500 $\mathrm{mg} / \mathrm{kg}$ of SAB was administered orally in conscious and freely moving rats. The oral bioavailability of SAB was found to be $2.3 \%$ in freely moving rats [148]. Fluorescent poly (ethyl-cyanoacrylate) nanoparticles (300 nm size) were loaded with $\mathrm{SAB}$ and it enhanced the bioavailability and sustenance of SAB and allowed the nano formulation to cross blood-brain barrier [149].

\section{Approaches to ameliorate the bioavailability of SAB}

The low bioavailability of SAB can be correlated to the rapid metabolic clearance or its poor absorption in the body. However, two main strategies can be adopted to enhance the SAB absorption, i.e. preparation of fat-soluble complexes and the use of absorption enhancers. The sodium caprateused as co-administration of absorption enhancer can significantly increase the intestinal permeability with the in vivo bioavailability of SAB [147]. Borneol is a common Chinese herbal medicine, which can improve the intestinal absorption of SAB in a dose-dependent manner $[150,151]$. The production of fat-soluble complexes such as phospholipids may possibly be another suitable preference that can enhance the absorption of SAB in GI tract. This can be attained through the phospholipid complex loaded with the nanoparticle formation. This formulated complex can lead to an increase of 2.9 folds in the relative bioavailability in comparison to the normal salvianolic acid $B$ formulation [152]. Increased bioavailability of SAB has been reported using SAB phospholipid complex loaded pellets without causing any significant increase in $C_{\max }$ when compared to SAB alone $[153,154]$. This finding supports the utilization of nanoparticle establishment that produces a greater bioavailability than the pellet formation.

The two major metabolites of $S A B$ produced after it was injected intravenously in rats are, i.e. monomethylSAB (3-MMS) and Lithospermic acid (LSA). The metabolic pathway for SAB in rats included methylation by means of catechol- $O$-methyltransferase (COMT) in kidney and liver [152]. The blood concentration can greatly be increased in rats by co-administration of an intravenous dose of $50 \mathrm{mg} / \mathrm{kg} \mathrm{SAB}$ and $0.5 \mathrm{mg} / \mathrm{kg}$ ferulic acid [155]. Additionally, the accumulative absorption of SAB in the rats was increased from $3 \%$ to $40 \%$ in the bile excretion, when used with $L$-DOPA and tolcapone. Likewise, with the single intravenous dose of SAB, the plasma concentration of 3-O-methyl dopa (3-OMD) was noted to be decreased. The current information related to CYP enzymes and SAB is debatable. Qui et al. [156] revealed that SAB has no obvious effect on CYP enzyme using human liver microsomes (HLMs).

In contrast to previous study, $\mathrm{SAB}$ was reported to exhibit effectual concentration-dependent inhibitory effect on CYP3A4 activity with $\mathrm{IC}_{50}$ values of $1.44 \mathrm{mg} / \mathrm{L}$ on HLMs thus demonstrating the role of CYP3A4 substrate [157]. Ferulic acid nano particles (FA-NPs) loaded with SAB displayed significantly stronger antitumor effects via receptor-mediated targeted delivery in MCF-7 and MDA-MB-231 cells [158]. Two 
novel analogs of SAB were recently isolated from salvianolic acid injection. $7^{\prime}(Z)-\left(8^{\prime \prime} S, 8^{\prime \prime \prime} S\right)$-epi-salvianolic acid $\mathrm{E}$ (compound 1 ) is a ring opened product of $\mathrm{SAB}$ and $\left(7^{\prime} R, 8^{\prime} R, 8^{\prime \prime} S, 8^{\prime \prime \prime} S\right.$ )-epi-salvianolic acid $\mathrm{B}$ (compound 2 ) is a non-enantiomer of SAB (Figure 5). Both these compounds were around $6 \%$ of total SAB injection. Compound 1 showed neuroprotective effects comparative to SAB while compound 2 exhibited potent antioxidants effects [159]. Pharmacokinetics study on both SAB analogs and SAB showed that at a dose of $6 \mathrm{mg} / \mathrm{kg}$, compound 1 and compound 2 had a slow elimination rate than SAB. Interestingly, compound 1 and SAB had higher exposure at the same dosage than compound 2. These findings showed the potential therapeutic role of novel analogs of SAB [160].<smiles>O=C(/C=C/c1ccc(O)c(O)c1/C(=C/c1ccc(O)c(O)c1)C(=O)O[C@H](Cc1ccc(O)c(O)c1)C(=O)O)O[C@H](Cc1ccc(O)c(O)c1)C(=O)O</smiles>

$7^{\prime}(Z)-\left(8^{\prime \prime} S, 8^{\prime \prime \prime}\right)$-epi-salvianolic acid E

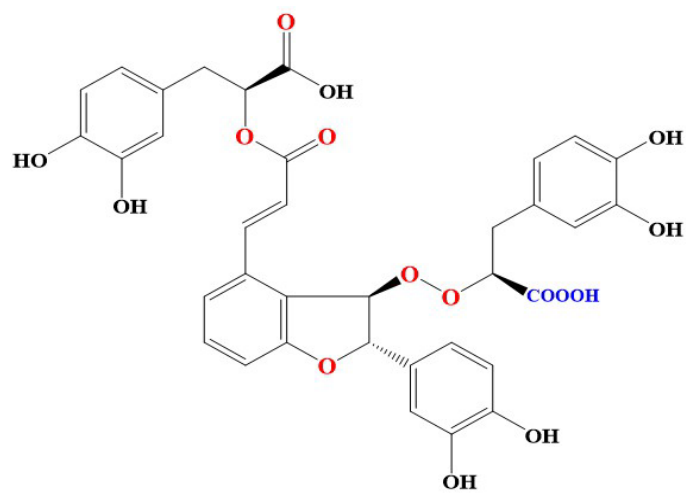

$\left(7^{\prime} R, 8^{\prime} R, 8^{\prime \prime} S, 8^{\prime \prime \prime} S\right)$-epi-salvianolic acid B

Figure 5. Chemical structures of salvianolic acid $B$ analogues

\section{Biosafety profile of SAB}

Biosafety and toxic profiling of SAB in rats showed significant adverse effects in lungs, liver, kidney, brain, and heart after administration of $\mathrm{SAB}$ in combination with ginsenoside $\operatorname{Rg} 1$ at a lethal dose $\left(\mathrm{LD}_{50}\right)$ of 1,747 $\mathrm{mg} / \mathrm{kg}$. This dose is 100 times more than the effective dose of SAB [161]. Many clinical trial studies have cleared S. miltiorrhiza for the treatment of stroke, heart attack, and many other clinical pathologies [162]. As a non-toxic and bio-safe ingredient in a traditional medicine being used for a century, SAB has primarily emerged as a safe drug for clinical use. However, additional studies are required to explore and validate its safety for human use.

\section{Conclusion and Future perspectives}

The cancer has created havoc for the humanity and its treatment has baffled scientists and researchers for past many decades. The use of natural compounds to treat different types of cancers has a promising future, as these compounds can be effective at doses, which are likely to cause lesser adverse effects. SAB provides an alternative to already existing therapies for different typed of cancer due to its ability to target multiple cellular pathways, i.e. MAPK, PI3K/AKT, and NF-kB to induce apoptosis, inhibit invasion and proliferation of tumor cells. It can also sensitize tumor cells to other antitumor agents by reversing the multi-drug resistance mechanisms operational in tumor cells. The limitation of bioavailability of SAB is a major hurdle for its use in treatment, which can be overcome by using nanoparticles-based drug delivery systems to enhance its efficacy and retention in the living systems. Further pre-clinical and clinical studies are essential to cement the idea that SAB can be used effectively in therapy of different types of cancers.

\section{Abbreviations}

5-FU: 5-fluorouracil

AKT: protein kinase B

ATO: arsenic trioxide

BAX: BCL-2-associated X protein

BCL-2: B-cell lymphoma-2 
Cox-2: cyclooxygenase-2

DMBA: 7, 12-dimethylbenzanthracene

EMT: epithelial-mesenchymal transition

ESC: Ehrlich solid carcinoma cell line

HCC: hepatocellular carcinoma

HIF: hypoxia induced factor

HNSCC: head and neck squamous cell carcinoma

$\mathrm{IC}_{50}$ : concentration needed to kill cells by $50 \%$ as compared to untreated control

MAPK: mitogen-activated protein kinase

MMP: matrix metalloproteinase

NF-кB: nuclear factor kappa light chain enhancer of activated B cells

OSCC: oral squamous cell carcinoma

PARP: poly ADP-ribose polymerase

PI3K: phosphatidylinositol 3-kinase

S. miltiorrhiza: Salvia miltiorrhiza

SAB: salvianolic acid B

SCC: squamous cell carcinoma

TGF: transforming growth factor

TNF: tumor necrosis factor

VEGF: vascular endothelial growth factor

\section{Declarations}

\section{Author contributions}

This manuscript has been written by IS, ZA and SB. It was edited by BM, ASN and RM. All authors have read and agreed to the published version of the manuscript.

\section{Conflicts of interest}

The authors declare that there are no conflicts of interest.

\section{Ethical approval}

Not applicable.

\section{Consent to participate}

Not applicable.

\section{Consent to publication}

Not applicable.

\section{Availability of data and materials}

Not applicable.

\section{Funding}

This work was supported by Higher Education Commission of Pakistan (HEC) grant. The funder had no role in study design, data collection and analysis, decision to publish, or preparation of the manuscript.

\section{Copyright}

(C) The Author(s) 2020. 


\section{References}

1. Siegel RL, Miller KD, Jemal A. Cancer statistics, 2020. CA Cancer J Clin. 2020;70:7-30.

2. World Health Organization. WHO report on cancer: setting priorities, investing wisely and providing care for all. 2020. https://www.who.int/publications/i/item/who-report-on-cancer-setting-prioritiesinvesting-wisely-and-providing-care-for-all. [Last accessed on $30 \mathrm{Apr} 2020$ ].

3. Fidler MM, Bray F, Soerjomataram I. The global cancer burden and human development: a review. Scand J Public Health. 2018;46:27-36.

4. Ramachandran L, Manu KA, Shanmugam MK, Li F, Siveen KS, Vali S, et al. Isorhamnetin inhibits proliferation and invasion and induces apoptosis through the modulation of peroxisome proliferatoractivated receptor $\gamma$ activation pathway in gastric cancer. J Biol Chem. 2012;287:38028-40.

5. Mishra S, Verma SS, Rai V, Awasthee N, Chava S, Hui KM, et al. Long non-coding RNAs are emerging targets of phytochemicals for cancer and other chronic diseases. Cell Mol Life Sci. 2019;76:1947-66.

6. Rajendran P, Li F, Shanmugam MK, Vali S, Abbasi T, Kapoor S, et al. Honokiol inhibits signal transducer and activator of transcription-3 signaling, proliferation, and survival of hepatocellular carcinoma cells via the protein tyrosine phosphatase SHP-1. J Cell Physiol. 2012;227:2184-95.

7. Hanahan D, Weinberg RA. The hallmarks of cancer. Cell. 2000;100:57-70.

8. Manu KA, Shanmugam MK, Ramachandran L, Li F, Siveen KS, Chinnathambi A, et al. Isorhamnetin augments the anti-tumor effect of capeciatbine through the negative regulation of NF- $\mathrm{KB}$ signaling cascade in gastric cancer. Cancer Lett. 2015;363:28-36.

9. Raphael MJ, Siemens R, Peng Y, Vera-Badillo FE, Booth CM. Volume of systemic cancer therapy delivery and outcomes of patients with solid tumors: a systematic review and methodologic evaluation of the literature. J Cancer Policy. 2020;23:100215.

10. Mohan CD, Rangappa S, Preetham HD, Chandra Nayak S, Gupta VK, Basappa S, et al. Targeting STAT3 signaling pathway in cancer by agents derived from Mother Nature. Semin Cancer Bio. 2020;[Epub ahead of print].

11. Loh CY, Arya A, Naema AF, Wong WF, Sethi G, Looi CY. Signal transducer and activator of transcription (STATs) proteins in cancer and inflammation: functions and therapeutic implication. Front Oncol. 2019;9:48.

12. Prasannan R, Kalesh KA, Shanmugam MK, Nachiyappan A, Ramachandran L, Nguyen AH, et al. Key cell signaling pathways modulated by zerumbone: role in the prevention and treatment of cancer. Biochem Pharmacol. 2012;84:1268-76.

13. Shanmugam MK, Kannaiyan R, Sethi G. Targeting cell signaling and apoptotic pathways by dietary agents: role in the prevention and treatment of cancer. Nutr Cancer. 2011;63:161-73.

14. Kroschinsky F, Stölzel F, von Bonin S, Beutel G, Kochanek M, Kiehl M, et al. New drugs, new toxicities: severe side effects of modern targeted and immunotherapy of cancer and their management. Crit Care. 2017;21:89.

15. Magge RS, DeAngelis LM. The double-edged sword: neurotoxicity of chemotherapy. Blood Rev. 2015;29:93-100.

16. Onakpoya IJ, Heneghan CJ, Aronson JK. Post-marketing withdrawal of 462 medicinal products because of adverse drug reactions: a systematic review of the world literature. BMC Med. 2016;14;10.

17. Pan H, Gray R, Braybrooke J, Davies C, Taylor C, McGale P, et al. 20-year risks of breast-cancer recurrence after stopping endocrine therapy at 5 years. N Engl J Med. 2017;377:1836-46.

18. Patwardhan B, Gautam M. Botanical immunodrugs: scope and opportunities. Drug Discov Today. 2005;10:495-502. 
19. Manu KA, Shanmugam MK, Li F, Chen L, Siveen KS, Ahn KS, et al. Simvastatin sensitizes human gastric cancer xenograft in nude mice to capecitabine by suppressing nuclear factor-kappa B-regulated gene products. J Mol Med (Berl). 2014;92:267-76.

20. Jung YY, Lee JH, Nam D, Narula AS, Namjoshi OA, Blough BE, et al. Anti-myeloma effects of icariin are mediated through the attenuation of JAK/STAT3-dependent signaling cascade. Front Pharmacol. 2018;9:531.

21. Li F, Shanmugam MK, Siveen KS, Wang F, Ong TH, Loo SY, et al. Garcinol sensitizes human head and neck carcinoma to cisplatin in a xenograft mouse model despite downregulation of proliferative biomarkers. Oncotarget. 2015;6:5147-63.

22. Zhang J, Ahn KS, Kim C, Shanmugam MK, Siveen KS, Arfuso F, et al. Nimbolide-induced oxidative stress abrogates STAT3 signaling cascade and inhibits tumor growth in transgenic adenocarcinoma of mouse prostate model. Antioxid Redox Signal. 2016;24:575-89.

23. Lee JH, Chiang SY, Nam D, ChungWS, Lee J, Na YS, etal. Capillarisin inhibits constitutive and inducible STAT3 activation through induction of SHP-1 and SHP-2 tyrosine phosphatases. Cancer Lett. 2014;345:140-8.

24. Patridge E, Gareiss P, Kinch MS, Hoyer D. An analysis of FDA-approved drugs: natural products and their derivatives. Drug Discov Today. 2016;21:204-7.

25. Siveen KS, Ahn KS, Ong TH, Shanmugam MK, Li F, Yap WN, et al. $\gamma$-tocotrienol inhibits angiogenesisdependent growth of human hepatocellular carcinoma through abrogation of AKT/mTOR pathway in an orthotopic mouse model. Oncotarget. 2014;5:1897-911.

26. Patel SM, Nagulapalli Venkata KC, Bhattacharyya P, Sethi G, Bishayee A. Potential of neem (Azadirachta indica L.) for prevention and treatment of oncologic diseases. Semin Cancer Biol. 2016;40-41:100-15.

27. Dai X, Zhang J, Arfuso F, Chinnathambi A, Zayed ME, Alharbi SA, et al. Targeting TNF-related apoptosisinducing ligand (TRAIL) receptor by natural products as a potential therapeutic approach for cancer therapy. Exp Biol Med (Maywood). 2015;240:760-73.

28. Li YG, Song L, Liu M, Hu ZB, Wang ZT. Advancement in analysis of Salviae miltiorrhizae Radix et Rhizoma (Danshen). J Chromatogr A. 2009;1216:1941-53.

29. Zhou L, Zuo Z, Chow MSS. Danshen: an overview of its chemistry, pharmacology, pharmacokinetics, and clinical use. J Clin Pharmacol. 2005;45:1345-59.

30. Liu J, Shen HM, Ong CN. Salvia miltiorrhiza inhibits cell growth and induces apoptosis in human hepatoma HepG2 cells. Cancer Lett. 2000;153:85-93.

31. Ma L, Tang L, Yi Q. Salvianolic acids: potential source of natural drugs for the treatment of fibrosis disease and cancer. Front Pharmacol. 2019;10:97.

32. Cheng TO. Cardiovascular effects of Danshen. Int J Cardiol. 2007;121:9-22.

33. Lin TH, Hsieh CL. Pharmacological effects of Salvia miltiorrhiza (Danshen) on cerebral infarction. Chin Med. 2010;5:22

34. Lien EJ, Ren S, Bui HH, Wang R. Quantitative structure-activity relationship analysis of phenolic antioxidants. Free Radic Biol Med. 1999;26:285-94.

35. Li MH, Chen JM, Peng Y, Xiao PG. Distribution of phenolic acids in Chinese salvia plants. World Sci Technol. 2008;10:46-52.

36. Wang X, Morris-Natschke SL, Lee KH. New developments in the chemistry and biology of the bioactive constituents of Tanshen. Med Res Rev. 2007;27:133-48.

37. Du G, Song J, Du L, Zhang L, Qiang G, Wang S, et al. Chemical and pharmacological research on the polyphenol acids isolated from Danshen: a review of salvianolic acids. Adv Pharmacol. 2020;87;1-41.

38. Cao W, Guo XW, Zheng HZ, Li DP, Jia GB, Wang J. Current progress of research on pharmacologic actions of salvianolic acid B. Chin J Integr Med. 2012;18:316-20. 
39. Tang MK, Ren DC, Zhang JT, Du GH. Effect of salvianolic acids from Radix Salviae miltiorrhizae on regional cerebral blood flow and platelet aggregation in rats. Phytomed. 2002;9:405-9.

40. Durairajan SSK, Yuan Q, Xie L, Chan WS, Kum WF, Koo I, et al. Salvianolic acid B inhibits A $\beta$ fibril formation and disaggregates preformed fibrils and protects against $A \beta$-induced cytotoxicty. Neurochem Int. 2008;52:741-50.

41. Ai CB, Li LN. Stereostructure of salvianolic acid B and isolation of salvianolic acid C from Salvia miltiorrhiza. J Nat Prod. 1988;51:145-9.

42. Garcia CSC, Menti C, Lambert APF, Barcellos T, Moura S, Calloni C, et al. Pharmacological perspectives from Brazilian Salvia officinalis (Lamiaceae): antioxidant, and antitumor in mammalian cells. An Acad Bras Cienc. 2016;88:281-92.

43. Huang YS, Zhang JT. Antioxidative effect of three water-soluble components isolated from Salvia miltiorrhiza in vitro. Acta pharmaceutica Sinica. 1992;27:96-100.

44. Zhao GR, Zhang HM, Ye TX, Xiang ZJ, Yuan YJ, Guo ZX, et al. Characterization of the radical scavenging and antioxidant activities of danshensu and salvianolic acid B. Food Chem Toxicol. 2008;46:73-81.

45. Shanbhag VKL. Tanshinones in management of oral submucous fibrosis and oral squamous cell carcinoma. Oncobiology and Targets. 2017;04:456966.

46. Shi M, Huang F, Deng C, Wang Y, Kai G. Bioactivities, biosynthesis and biotechnological production of phenolic acids in Salvia miltiorrhiza. Crit Rev Food Sci Nutr. 2019;59:953-64.

47. Petersen M, Häusler E, Karwatzki B, Meinhard J. Proposed biosynthetic pathway for rosmarinic acid in cell cultures of Coleus blumei Benth. Planta. 1993;189:10-4.

48. Wang FM, Li L, Liu XP, Wang XR, Li XC. Extraction of Salvianolic acid B from Danshen (Salvia Miltiorrhiza Bge.) and determination by HPLC method. Res Pract Chin Med. 2004;S1:62-4. Chinese.

49. Dong J, Liu Y, Liang Z, Wang W. Investigation on ultrasound-assisted extraction of salvianolic acid B from Salvia miltiorrhiza root. Ultrason Sonochem. 2010;17:61-5.

50. Fouad YA, Aanei C. Revisiting the hallmarks of cancer. Am J Cancer Res. 2017;7:1016-36.

51. Qin T, Rasul A, Sarfraz A, Sarfraz I, Hussain G, Anwar H, et al. Salvianolic acid A \& B: potential cytotoxic polyphenols in battle against cancer via targeting multiple signaling pathways. Int J Biol Sci. 2019;15:2256-64.

52. Kirtonia A, Sethi G, Garg M. The multifaceted role of reactive oxygen species in tumorigenesis. Cell Mol Life Sci. 2020;[Epub ahead of print].

53. Aggarwal V, Tuli HS, Varol A, Thakral F, Yerer MB, Sak K, et al. Role of reactive oxygen species in cancer progression: molecular mechanisms and recent advancements. Biomolecules. 2019;9:735.

54. Dai X, Wang L, Deivasigamni A, Looi CY, Karthikeyan C, Trivedi P, et al. A novel benzimidazole derivative, MBIC inhibits tumor growth and promotes apoptosis via activation of ROS-dependent JNK signaling pathway in hepatocellular carcinoma. Oncotarget. 2017;8:12831-42.

55. Kim C, Lee SG, Yang WM, Arfuso F, Um JY, Kumar AP, et al. Formononetin-induced oxidative stress abrogates the activation of STAT3/5 signaling axis and suppresses the tumor growth in multiple myeloma preclinical model. Cancer Lett. 2018;431:123-41.

56. Yan F. Effects of salvianolic acid B on growth inhibition and apoptosis induction of ovarian cancer SKOV3. Eur J Gynaecol Oncol. 2016;1;37:653-6.

57. Hao Y, Xie T, Korotcov A, Zhou Y, Pang X, Shan L, et al. Salvianolic acid B inhibits growth of head and neck squamous cell carcinoma in vitro and in vivo via cyclooxygenase-2 and apoptotic pathways. Int J Cancer. 2009;124:2200-9.

58. Zhao Y, Hao Y, Ji H, Fang Y, Guo Y, Sha W, et al. Combination effects of salvianolic acid B with low-dose celecoxib on inhibition of head and neck squamous cell carcinoma growth in vitro and in vivo. Cancer Prev Res (Phila). 2010;3:787-96. 
59. Lee JH, Kim C, Um JY, Sethi G, Ahn KS. Casticin-induced inhibition of cell growth and survival are mediated through the dual modulation of Akt/mTOR signaling cascade. Cancers (Basel). 2019;11:254.

60. Gong L, Di C, Xia X, Wang J, Chen G, Shi J, et al. AKT/mTOR signaling pathway is involved in salvianolic acid B-induced autophagy and apoptosis in hepatocellular carcinoma cells. Int J Oncol. 2016;49:253848.

61. Ong PS, Wang LZ, Dai X, Tseng SH, Loo SJ, Sethi G. Judicious toggling of mTOR activity to combat insulin resistance and cancer: current evidence and perspectives. Front Pharmacol. 2016;7:395.

62. Mohan CD, Srinivasa V, Rangappa S, Mervin L, Mohan S, Paricharak S, et al. Trisubstituted-imidazoles induce apoptosis in human breast cancer cells by targeting the oncogenic PI3K/Akt/mTOR signaling pathway. PLoS One. 2016;11:e153155.

63. Jing Z, Fei W, Zhou J, Zhang L, Chen L, Zhang X, et al. Salvianolic acid B, a novel autophagy inducer, exerts antitumor activity as a single agent in colorectal cancer cells. Oncotarget. 2016;7:61509-19.

64. Mizushima N, Levine B, Cuervo AM, Klionsky DJ. Autophagy fights disease through cellular self-digestion. Nature. 2008;451:1069-75.

65. Rosenfeldt MT, Ryan KM. The multiple roles of autophagy in cancer. Carcinogenesis. 2011;32:955-63.

66. Wang C, Cigliano A, Jiang L, Li X, Fan B, Pilo MG, et al. 4EBP1/eIF4E and p70S6K/RPS6 axes play critical and distinct roles in hepatocarcinogenesis driven by AKT and N-Ras proto-oncogenes in mice. Hepatology. 2015;61:200-13.

67. Xia Y, Shen S, Verma IM. NF- $\kappa B$, an active player in human cancers. Cancer Immunol Res. 2014;2:823-30.

68. Puar YR, Shanmugam MF, Fan L, Arfuso F, Sethi G, Tergaonkar V. Evidence for the involvement of the master transcription factor NF- $\mathrm{KB}$ in cancer initiation and progression. Biomedicines. 2018;6:82.

69. Sethi G, Ahn KS, Sung B, Aggarwal BB. Pinitol targets nuclear factor- $\kappa B$ activation pathway leading to inhibition of gene products associated with proliferation, apoptosis, invasion, and angiogenesis. Mol Cancer Ther. 2008;7:1604-14.

70. Chua AWL, Hay HS, Rajendran P, Shanmugam MK, Li F, Bist P, et al. Butein downregulates chemokine receptor CXCR4 expression and function through suppression of NF- $\mathrm{KB}$ activation in breast and pancreatic tumor cells. Biochem Pharmacol. 2010;80:1553-62.

71. Shanmugam MK, Manu KA, Ong TH, Ramachandran L, Surana R, Bist P, et al. Inhibition of CXCR4/CXCL12 signaling axis by ursolic acid leads to suppression of metastasis in transgenic adenocarcinoma of mouse prostate model. Int J Cancer. 2011;129:1552-63.

72. Siveen KS, Mustafa N, Li F, Kannaiyan R, Ahn KS, Kumar AP, et al. Thymoquinone overcomes chemoresistance and enhances the anticancer effects of bortezomib through abrogation of NF- $\mathrm{KB}$ regulated gene products in multiple myeloma xenograft mouse model. Oncotarget. 2014;5:634-48.

73. Wong ALA, Hirpara JL, Pervaiz S, Eu JQ, Sethi G, Goh BC. Do STAT3 inhibitors have potential in the future for cancer therapy? Expert Opin Investig Drugs. 2017;26:883-7.

74. Checker R, Sandur SK, Sharma D, Patwardhan RS, Jayakumar S, Kohli V, et al. Potent anti-inflammatory activity of ursolic acid, a triterpenoid antioxidant, is mediated through suppression of NF- $\mathrm{KB}, \mathrm{AP}-1$ and NF-AT. PLoS One. 2012;7:e31318.

75. Yang Y, Ge PJ, Jiang L, Li FL, Zhu QY. Modulation of growth and angiogenic potential of oral squamous carcinoma cells in vitro using salvianolic acid B. BMC Complement Altern Med. 2011;11:54.

76. Wei J, Xie G, Ge S, Qiu Y, Liu W, Lu A, et al. Metabolic transformation of DMBA-induced carcinogenesis and inhibitory effect of salvianolic acid B and breviscapine treatment. J Proteome Res. 2012;11:1302-16.

77. DeSantis CE, Bray F, Ferlay J, Lortet-Tieulent J, Anderson BO, Jemal A. International variation in female breast cancer incidence and mortality rates. Cancer Epidemiol Biomarkers Prev. 2015;24:1495-506.

78. Shanmugam MK, Ahn KS, Hsu A, Woo CC, Yuan Y, Tan KHB, et al. Thymoquinone inhibits bone metastasis of breast cancer cells through abrogation of the CXCR4 signaling axis. Front Pharmacol. 2018;9:1294. 
79. Shin EM, Hay HS, Lee MH, Goh JN, Tan TZ, Sen YP, et al. DEAD-box helicase DP103 defines metastatic potential of human breast cancers. J Clin Invest. 2014;124:3807-24.

80. Bhuvanalakshmi G, Basappa, Rangappa KS, Dharmarajan A, Sethi G, Kumar AP, et al. Breast cancer stemlike cells are inhibited by diosgenin, a steroidal saponin, by the attenuation of the Wnt $\beta$-catenin signaling via the Wnt antagonist secreted frizzled related protein-4. Front Pharmacol. 2017;8:124.

81. Jia LY, Shanmugam MK, Sethi G, Bishayee A. Potential role of targeted therapies in the treatment of triplenegative breast cancer. Anticancer Drugs. 2016;27:147-55.

82. Parikh NR, Mandal A, Bhatia D, Siveen KS, Sethi G, Bishayee A. Oleanane triterpenoids in the prevention and therapy of breast cancer: current evidence and future perspectives. Phytochem Rev. 2014;13:793810.

83. Katary MA, Abdelsayed R, Alhashim A, Abdelhasib M, Elmarakby AA. Salvianolic acid B slows the progression of breast cancer cell growth via enhancement of apoptosis and reduction of oxidative stress, inflammation, and angiogenesis. Int J Mol Sci. 2019;20:5653.

84. Sha W, Zhou Y, Ling ZQ, Xie G, Pang X, Wang P, et al. Antitumor properties of Salvianolic acid B against triple-negative and hormone receptor-positive breast cancer cells via ceramide-mediated apoptosis. Oncotarget. 2018;9:36331-43.

85. Fares N, Péron JM. Epidemiology, natural history, and risk factors of hepatocellular carcinoma. Rev Prat. 2013;63:216-7, 220-2. French.

86. Rajendran P, Li F, Manu KA, Shanmugam MK, Loo SY, Kumar AP, et al. $\gamma$-Tocotrienol is a novel inhibitor of constitutive and inducible STAT3 signalling pathway in human hepatocellular carcinoma: potential role as an antiproliferative, pro-apoptotic and chemosensitizing agent. Br J Pharmacol. 2011;163:283-98.

87. Dai X, Ahn KS, Wang LZ, Kim C, Deivasigamni A, Arfuso F, et al. Ascochlorin enhances the sensitivity of doxorubicin leading to the reversal of epithelial-to-mesenchymal transition in hepatocellular carcinoma. Mol Cancer Ther. 2016;15:2966-76.

88. Raza A, Sood GK. Hepatocellular carcinoma review: current treatment, and evidence-based medicine. World J Gastroenterol. 2014;20:4115-27.

89. Sethi G, Chatterjee S, Rajendran P, Li F, Shanmugam MK, Wong KF, et al. Inhibition of STAT3 dimerization and acetylation by garcinol suppresses the growth of human hepatocellular carcinoma in vitro and in vivo. Mol Cancer. 2014;13:66.

90. Swamy SG, Kameshwar VH, Shubha PB, Looi CY, Shanmugam MK, Arfuso F, et al. Targeting multiple oncogenic pathways for the treatment of hepatocellular carcinoma. Target Oncol. 2017;12:1-10.

91. Dai X, Ahn KS, Kim C, Siveen KS, Ong TH, Shanmugam MK, et al. Ascochlorin, an isoprenoid antibiotic inhibits growth and invasion of hepatocellular carcinoma by targeting STAT3 signaling cascade through the induction of PIAS3. Mol Oncol. 2015;9:818-33.

92. Mastron JK, Siveen KS, Sethi G, Bishayee A. Silymarin and hepatocellular carcinoma: a systematic, comprehensive, and critical review. Anticancer Drugs. 2015;26:475-86.

93. Mohan CD, Bharathkumar H, Bulusu KC, Pandey V, Rangappa S, Fuchs JE, et al. Development of a novel azaspirane that targets the Janus kinase-signal transducer and activator of transcription (STAT) pathway in hepatocellular carcinoma in vitro and in vivo. J Biol Chem. 2014;289:34296-307.

94. Shi Y, Pan D, Yan L, Chen H, Zhang X, Yuan J, et al. Salvianolic acid B improved insulin resistance through suppression of hepatic ER stress in ob/ob mice. Biochem Biophys Res Commun. 2020;4:733-7.

95. Wang QL, Wu Q, Tao YY, Liu CH, El-Nezami H. Salvianolic acid B modulates the expression of drugmetabolizing enzymes in HepG2 cells. Hepatobiliary Pancreat Dis Int. 2011;10:502-8.

96. Wang M, Sun G, Wu P, Chen R, Yao F, Qin M, et al. Salvianolic acid B prevents arsenic trioxide-induced cardiotoxicity in vivo and enhances its anticancer activity in vitro. Evid Based Complement Alternat Med. 2013;2013:759483. 
97. Pai SI, Westra WH. Molecular pathology of head and neck cancer: implications for diagnosis, prognosis, and treatment. Annu Rev Pathol. 2009;4:49-70.

98. Selvi RB, Swaminathan A, Chatterjee S, Shanmugam MK, Li F, Ramakrishnan GB, et al. Inhibition of p300 lysine acetyltransferase activity by luteolin reduces tumor growth in head and neck squamous cell carcinoma (HNSCC) xenograft mouse model. Oncotarget. 2015;6:43806-18.

99. Lee JH, Rangappa S, Mohan CD, Basappa, Sethi G, Lin ZX, et al. Brusatol, a Nrf2 inhibitor targets STAT3 signaling cascade in head and neck squamous cell carcinoma. Biomolecules. 2019;9:550.

100. Hsu PJ, Yan K, Shi H, Izumchenko E, Agrawal N. Molecular biology of oral cavity squamous cell carcinoma. Oral Oncol. 2020;102:104552.

101. Li F, Shanmugam MK, Chen L, Chatterjee S, Basha J, Kumar AP, et al. Garcinol, a polyisoprenylated benzophenone modulates multiple proinflammatory signaling cascades leading to the suppression of growth and survival of head and neck carcinoma. Cancer Prev Res (Phila). 2013;6:843-54.

102. Baek SH, Ko JH, Lee H, Jung J, Kong M, Lee JW, et al. Resveratrol inhibits STAT3 signaling pathway through the induction of SOCS-1: role in apoptosis induction and radiosensitization in head and neck tumor cells. Phytomedicine. 2016;23:566-77.

103. Zhao Y, Guo Y, Gu X. Salvianolic acid B, a potential chemopreventive agent, for head and neck squamous cell cancer. J Oncol. 2011;2011:534548.

104. Ooi $\mathrm{CH}$, Ivanova $\mathrm{T}, \mathrm{Wu}$ J, Lee $\mathrm{M}$, Tan IB, Tao J, et al. Oncogenic pathway combinations predict clinical prognosis in gastric cancer. PLoS Genet. 2009;5:e1000676.

105. Siegel RL, Miller KD, Jemal A. Cancer statistics, 2016. CA Cancer J Clin. 2016;66:7-30.

106. Perrott S, Laurie K, Laws K, Johnes A, Miedzybrodzka Z, Samuel L. Young-onset colorectal cancer in the North East of Scotland: survival, clinico-pathological features and genetics. BMC Cancer. 2020;20:108.

107. Guo P, Wang S, Liang W, Wang W, Wang H, Zhao M, et al. Salvianolic acid B reverses multidrug resistance in HCT-8/VCR human colorectal cancer cells by increasing ROS levels. Mol Med Rep. 2017;15:724-30.

108. Guo P, Wang J, Gao W, Liu X, Wu S, Wan B, et al. Salvianolic acid B reverses multidrug resistance in nude mice bearing human colon cancer stem cells. Mol Med Rep. 2018;18:1323-34.

109. Bhuvanalakshmi G, Gamit N, Patil M, Arfuso F, Sethi G, Dharmarajan A, et al. Stemness, pluripotentiality, and Wnt antagonism: sFRP4, a Wnt antagonist mediates pluripotency and stemness in glioblastoma. Cancers (Basel). 2018;11:25.

110. Cloughesy TF, Cavenee WK, Mischel PS. Glioblastoma: from molecular pathology to targeted treatment. Annu Rev Pathol Mech Dis. 2014;9:1-25.

111. Wang ZS, Luo P, Dai SH, Liu ZB, Zheng XR, Chen T. Salvianolic acid B induces apoptosis in human glioma U87 cells through p38-mediated ROS generation. Cell Mol Neurobiol. 2013;33:921-8.

112. Chen W, Wang N, Li RC, Xu GF, Bao G, Jiang HT, et al. Salvianolic acid B renders glioma cells more sensitive to radiation via Fis-1-mediated mitochondrial dysfunction. Biomed Pharmacother. 2018;107:1230-6.

113. Ningegowda R, Shivananju NS, Rajendran P, Basappa, Rangappa KS, Chinnathambi A, et al. A novel 4,6-disubstituted-1,2,4-triazolo-1,3,4-thiadiazole derivative inhibits tumor cell invasion and potentiates the apoptotic effect of TNF $\alpha$ by abrogating NF-KB activation cascade. Apoptosis. 2017;22:145-57.

114. Webb PM, Green AC, Jordan SJ. Trends in hormone use and ovarian cancer incidence in US white and Australian women: implications for the future. Cancer Causes Control. 2017;28:365-70.

115. Jelovac D, Armstrong DK. Recent progress in the diagnosis and treatment of ovarian cancer. CA Cancer J Clin. 2011;61:183-203.

116. Aerts I, Lumbroso-Le Rouic L, Gauthier-Villars M, Brisse H, Doz F, Desjardins L. Retinoblastoma. Orphanet J Rare Dis. 2006;1:31.

117. Liu XA. Effects of salvianolic acid B on in vitro growth inhibition and apoptosis induction of retinoblastoma cells. Int J Ophthalmol. 2012;5:272-6 
118. Sinha N, Panda PK, Naik PP, Das DN, Mukhopadhyay S, Maiti TK, et al. Abrus agglutinin promotes irreparable DNA damage by triggering ROS generation followed by ATM-p73 mediated apoptosis in oral squamous cell carcinoma. Mol Carcinog. 2017;56:2400-13.

119. Warnakulasuriya S. Global epidemiology of oral and oropharyngeal cancer. Oral Oncol. 2009;45:309-16.

120. Behera AK, Kumar M, Shanmugam MK, Bhattacharya A, Rao VJ, Bhat A, et al. Functional interplay between YY1 and CARM1 promotes oral carcinogenesis. Oncotarget. 2019;10:3709-24.

121. Sawhney M, Rohatgi N, Kaur J, Shishodia S, Sethi G, Gupta SD, et al. Expression of NF- $\kappa B$ parallels COX-2 expression in oral precancer and cancer: association with smokeless tobacco. Int J Cancer. 2007;120:2545-56.

122. Zhou ZT, Yang Y, Ge JP. The preventive effect of salvianolic acid B on malignant transformation of DMBAinduced oral premalignant lesion in hamsters. Carcinogenesis. 2006;27:826-32.

123. Wei J, Wu J, Xu W, Nie H, Zhou R, Wang R, et al. Salvanic acid B inhibits glycolysis in oral squamous cell carcinoma via targeting PI3K/AKT/HIF-1 $\alpha$ signaling pathway. Cell Death Dis. 2018;9:599.

124. Tao L, Wang S, Zhao Y, Sheng X, Wang A, Zheng S, et al. Phenolcarboxylic acids from medicinal herbs exert anticancer effects through disruption of COX-2 activity. Phytomedicine. 2014;21:1473-82.

125. Guo L, Lei CK, Shan M. Study of growth inhibitory effect and apoptosis induced by different matches of Tanshinone IIA and Salvianolic acid B on acute promyelocytic leukemia cells (HL-60). Zhong Yao Cai. 2008;31:1512-4. Chinese.

126. Libring S, Shinde A, Chanda MK, Nuru M, George H, Saleh AM, et al. The dynamic relationship of breast cancer cells and fibroblasts in fibronectin accumulation at primary and metastatic tumor sites. Cancers (Basel). 2020;12:1270.

127. Uzunalli G, Dieterly AM, Kemet CM, Weng HY, Soepriatna AH,Goergen CJ, et al. Dynamic transition of the blood-brain barrier in the development of non-small cell lung cancer brain metastases. Oncotarget. 2019;10:6334-48.

128. Shinde A, Hardy SD, Kim D, Akhand SS, Jolly MK, Wang WH, et al. Spleen tyrosine kinase-mediated autophagy is required for epithelial-mesenchymal plasticity and metastasis in breast cancer. Cancer Res. 2019;79:1831-43.

129. Shinde A, Paez JS, Libring S, Hopkins K, Solorio L, Wendt MK. Transglutaminase-2 facilitates extracellular vesicle-mediated establishment of the metastatic niche. Oncogenesis. 2020;9:16.

130. Shinde A, Libring S, Alpsoy A, Abdullah A, Schaber JA, Solorio L, et al. Autocrine fibronectin inhibits breast cancer metastasis. Mol Cancer Res. 2018;16:1579-89.

131. Shinde A, Wilmanski T, Chen H, Teegarden D, Wendt MK. Pyruvate carboxylase supports the pulmonary tropism of metastatic breast cancer. Breast Cancer Res. 2018;20:76.

132. Hardy SD, Shinde A, Wang WH, Wendt MK, Geahlen RL. Regulation of epithelial-mesenchymal transition and metastasis by TGF- $\beta$, P-bodies, and autophagy. Oncotarget. 2017;8:103302-14.

133. Wilmanski T, Zhou X, Zheng W, Shinde A, Donkin SS, Wendt M, et al. Inhibition of pyruvate carboxylase by $1 \alpha, 25$-dihydroxyvitamin $\mathrm{D}$ promotes oxidative stress in early breast cancer progression. Cancer Lett. 2017;411:171-81.

134. Luo P, Tan Z, Zhang Z, Li H, Mo Z. Inhibitory effects of salvianolic acid B on the high glucose-induced mesangial proliferation via NF- $\kappa B-d e p e n d e n t$ pathway. Bio Pharm Bull. 2008;31:1381-6.

135. Yu F, Lu Z, Chen B, Wu X, Dong P, Zheng J. Salvianolic acid B-induced microRNA-152 inhibits liver fibrosis by attenuating DNMT 1-mediated Patched1 methylation. J Cell Mol Med. 2015;19:2617-32.

136. Tang Q Zhong H, Xie F, Xie J, Chen H, Yao G. Expression of miR-106b-25 induced by salvianolic acid B inhibits epithelial-to-mesenchymal transition in HK-2 cells. Eur J Pharmacol. 2014;741:97-103.

137. Wang QL, Tao YY, Yuan JL, Shen L, Liu CH. Salvianolic acid B prevents epithelial-to-mesenchymal transition through the TGF- $\beta 1$ signal transduction pathway in vivo and in vitro. BMC Cell Biol. 2010;11:31. 
138. Li J, Zhang C, He W, Qiao H, Chen J, Wang K, et al. Coordination-driven assembly of catechol-modified chitosan for the kidney-specific delivery of salvianolic acid B to treat renal fibrosis. Biomater Sci. 2017;6:179-88.

139. Brabletz T. EMT and MET in metastasis: where are the cancer stem cells? Cancer cell. 2012;22:699-701.

140. Kunnumakkara AB, Harsha C, Banik K, Vikkurthi R, Sailo BL, Bordoloi D, et al. Is curcumin bioavailability a problem in humans: lessons from clinical trials. Expert Opin Drug Metab Toxicol. 2019;15:705-33.

141. Zhang J, Yu H, Sheng Y, Li L, Ye M, Guo D. HPLC determination and pharmacokinetic studies of salvianolic acid B in rat plasma after oral administration of Radix Salviae miltiorrhizae extract. Biomed Chromatogr. 2005;19:15-8.

142. Gao DY, Han LM, Zhang LH, Fang XL, Wang JX. Bioavailability of salvianolic acid B and effect on blood viscosities after oral administration of salvianolic acids in beagle dogs. Arch Pharm Res. 2009;32:773-9.

143. Zhan Y, Xu JP, Liang JB, Sheng LS, Xiang BR, Zou QG, et al. Simultaneous LC-MS-MS analysis of danshensu, salvianolic acid B, and hydroxysafflor yellow A in beagle dog plasma, and application of the method to a pharmacokinetic study of danhong lyophilized powder for injection. Chromatographia. 2008;68:71-9.

144. Li X, Cheng C, Wang F, Huang Y, Jia W, Olaleye OE, et al. Pharmacokinetics of catechols in human subjects intravenously receiving XueBijing injection, an emerging antiseptic herbal medicine. Drug Metab Pharmacokinet. 2016;31:95-8.

145. Guo X, Chen X, Li L, Shen Z, Wang X, Zheng P, et al. LC-MS determination and pharmacokinetic study of six phenolic components in rat plasma after taking traditional Chinese medicinal-preparation: Guanxinning lyophilized powder for injection. J Chromatogr B Analyt Technol Biomed Life Sci. 2008;873:51-8.

146. Huang B, Li G, Guo YF, Wang SS, Liu F, Xu HY, et al. Study on absorption location of four components from Naoxintong capsule. Zhongguo Zhong Yao Za Zhi. 2013;38:889-93. Chinese.

147. Zhou L, Chow MSS, Zuo Z. Effect of sodium caprate on the oral absorptions of danshensu and salvianolic acid B. Int J Pharm. 2009;379:109-18.

148. Wu YT, Chen YF, Hsieh YJ, Jaw I, Shiao MS, Tsai TH. Bioavailability of salvianolic acid B in conscious and freely moving rats. Int J Pharm. 2006;326:25-31.

149. Grossi C, Guccione C, Isacchi B, Bergonzi MC, Luccarini I, Casamenti F, et al. Development of bloodbrain barrier permeable nanoparticles as potential carriers for salvianolic acid B to CNS. Planta Med. 2017;83:382-91.

150. Qi Q, Hao K, Li FY, Cao LJ, Wang GJ, Hao HP. The identification and pharmacokinetic studies of metabolites of salvianolic acid B after intravenous administration in rats. Chin J Nat Med. 2013;11:560-5.

151. Lai XJ, Zhang L, Li JS, Liu HQ, Liu XH, Di LQ et al. Comparative pharmacokinetic and bioavailability studies of three salvianolic acids after the administration of Salviae miltiorrhizae alone or with synthetical borneol in rats. Fitoterapia. 2011;82:883-8.

152. Abdelkawy KS, Lack K, Elbarbry F. Pharmacokinetics and pharmacodynamics of promising arginase inhibitors. Eur J Drug Metab Pharmacokinet. 2017;42:355-70.

153. He Q, Zhang J, Chen F, Guo L, Zhu Z, Shi J. An anti-ROS/hepatic fibrosis drug delivery system based on salvianolic acid B loaded mesoporous silica nanoparticles. Biomaterials. 2010;31:7785-96.

154. Peng Q Gong T, Zuo J, Liu J, Zhao D, Zhang Z. Enhanced oral bioavailability of salvianolic acid B by phospholipid complex loaded nanoparticles. Pharmazie. 2008;63:661-6.

155. Zhang CY, Zhang H, Dong Y, Ren WG, Chen HW. Study on compatibility of Salviae Miltiorrhizae Radix et Rhizoma and Chuanxiong Rhizoma based on pharmacokinetics of effective components salvianolic acid $B$ and ferulic acid in rat plasma. Zhongguo Zhong Yao Za Zhi. 2015;40:1589-93. Chinese.

156. Qiu F, Zhang R, Sun J, Jiye A, Hao H, Peng Y, et al. Inhibitory effects of seven components of danshen extract on catalytic activity of cytochrome P450 enzyme in human liver microsomes. Drug Metab Dispos. 2008;36:1308-14. 
157. Qin CZ, Ren X, Zhou HH, Mao XY, Liu ZQ. Inhibitory effect of salvianolate on human cytochrome P450 3A4 in vitro involving a noncompetitive manner. Int J Clin Exp Med. 2015;8:15549-55.

158. Ding L, Li J, Huang R, Liu Z, Li C, Yao S, et al. Salvianolic acid B protects against myocardial damage caused by nanocarrier Ti02; and synergistic anti-breast carcinoma effect with curcumin via codelivery system of folic acid-targeted and polyethylene glycol-modified Ti02 nanoparticles. Int J Nanomedicine. 2016;11:5709-27.

159. Si Y, Li N, Tong L, Lin B, Wang W, Xing Y, et al. Bioactive minor components of the total salvianolic acids injection prepared from Salvia miltiorrhiza Bge. Bioorganic Med Chem Lett. 2016;26:82-6.

160. Xie X, Sun W, Miao J, Huang J, Xu J, Liu X, et al. Development and validation of a UFLC-MS/MS method for determination of $7^{\prime}(Z)-\left(8^{\prime \prime} S, 8^{\prime \prime \prime} S\right)$-epi-salvianolic acid E, $\left(7^{\prime} R, 8^{\prime} R, 8^{\prime \prime} S, 8^{\prime \prime \prime} S\right)$-epi-salvianolic acid B and salvianolic acid $\mathrm{B}$ in rat plasma and its application to pharmacokinetic studies. J Chromatogr B. 2016;1022:6-12.

161. Zhao Q, Yang M, Deng Y, Yu H, Wang L, Teng F, et al. The safety evaluation of salvianolic acid B and ginsenoside Rg1 combination on mice. Int J Mol Sci. 2015;16:29345-56.

162. Adams JD, Wang R, Yang J, Lien EJ. Preclinical and clinical examinations of Salvia miltiorrhiza and its tanshinones in ischemic conditions. Chin Med. 2006;1:3. 